\title{
Major food sources contributing to energy intake - a nationwide survey of Brazilians aged 10 years and older
}

\author{
Rosely Sichieri ${ }^{1}$, Ilana Nogueira Bezerra ${ }^{2 *}$, Marina Campos Araújo ${ }^{3}$, Amanda de Moura Souza ${ }^{1}$, \\ Edna Massae Yokoo $^{4}$ and Rosangela Alves Pereira ${ }^{5}$ \\ ${ }^{1}$ Department of Epidemiology, Institute of Social Medicine, State University of Rio de Janeiro, Rua São Francisco Xavier, \\ 524, $7^{\circ}$ andar, Bloco E, Cep 20550-900, Rio de Janeiro, RJ, Brazil \\ ${ }^{2}$ Graduate Program in Public Health, University of Fortaleza, Avenida Washington Soares, 1321, Bloco S, Sala O1, \\ Cep 60.811-905, Fortaleza, CE, Brazil \\ ${ }^{3}$ Department of Epidemiology and Biostatistics, Institute of Community Health Studies, Federal University of Rio de Janeiro, \\ Avenida Horácio Macedo, S/N - Próximo a Prefeitura Universitária da UFRJ, Ilha do Fundão - Cidade Universitária, \\ Cep 21941-598, Rio de Janeiro, RJ, Brazil \\ ${ }^{4}$ Department of Epidemiology and Statistics, Institute of Community Health, Fluminense Federal University, Rua Marques de \\ Paraná, 303, $3^{\circ}$ andar, Predio Anexo, Centro, Cep 24030-210, Niteroi, RJ, Brazil \\ ${ }^{5}$ Department of Nutrition, Federal University of Rio de Janeiro, Avenida Carlos Chagas Filho, 373, Edificio do Centro de \\ Ciências da Saúde, Bloco J, $2^{\circ}$ andar, Cidade Universitária, Cep 21941-590, Rio de Janeiro, RJ, Brazil
}

(Submitted 15 October 2014 - Final revision received 26 January 2015 - Accepted 9 March 2015 - First published online 13 April 2015)

\begin{abstract}
Identification of major sources of energy in the diet helps to implement dietary recommendations to reduce obesity. To determine the food sources of energy consumed by Brazilians, we used the traditional method of ranking energy contribution of selected food groups and also compared days with and without consumption of specific food groups. Analysis was based on two non-consecutive days of dietary record from the Brazilian National Dietary Survey, conducted among 34003 Brazilians (aged 10 years or more), taking into account the complex design of the survey. Comparison of days with and without consumption gave more consistent results, with sweets and cookies as the most important contributors to energy intake, increasing $992 \mathrm{~kJ} / \mathrm{d}(95 \% \mathrm{CI} 883,1096)$ for those days when consumption of cakes, cookies and desserts was reported compared to days without their consumption. Savoury snacks, cheese and sugar-sweetened beverages (SSB) also increase energy intake by about $600 \mathrm{~kJ}$. The only group associated with decreased energy intake was vegetable $(-155 \mathrm{~kJ} ; 95 \% \mathrm{CI}$ $-272,-37)$. Consumption of beans, milk and fruits increased the energy intake by about $210 \mathrm{~kJ}$. In total, the mean energy intake of the group was $8000 \mathrm{~kJ}$. Except for the consumption of vegetables, all of the other ten food groups analysed were associated with increased energy intake. Sweets and cookies may increase the energy intake by $12 \%$ and SSB by $7 \%$, indicating that these two groups are major targets for improving healthy eating by reducing energy intake; whereas vegetable intake is associated with the reduction of energy content of the diet.
\end{abstract}

Key words: Healthy eating: Surveys: Food intake: Brazil

To provide nutrition education and dietary guidance to healthy individuals, many countries develop dietary guidelines for their population, focusing mainly on curbing the increasing rates of chronic diseases ${ }^{(1)}$. In general, dietary guidelines are the basis for nutrition policies and are an attempt to define the quality of a diet, usually combining general guidance on what food items should be included in a healthy diet with the necessary supply of nutrients. The epidemic of obesity has necessitated the development of strategies on how to decrease total energy intake, but clear messages on how to combine a healthy diet with low energy intake remain unavailable ${ }^{(1)}$. As a result, the guidelines in $\mathrm{Brazil}^{(2)}$ as well as in developed countries such as the United States ${ }^{(3)}$, Canada ${ }^{(4)}$ and $\mathrm{UK}^{(5)}$ lack clear indications on how to reduce energy intake.

Identifying the food groups that could be major contributors to excessive energy intake at the population level may help to generate dietary recommendations on reducing energy intake. Given that the condition of overweight and obesity has reached epidemic proportions in many countries, such recommendations are important. Studies identifying food sources of energy, such as the 2003-6 National Health and Nutrition Examination Survey ${ }^{(6)}$, or comparing between different countries in 
major contributors of energy ${ }^{(7)}$, have only ranked the foods based on 1-d measurements of food intake. In these ranked analysis, major contributors may simply reflect items consumed on a daily basis, such as rice. To overcome this methodological constraint, in the present study, we compared days with and without the consumption of specific food groups in the same individuals. To the best of our knowledge, this is the first analysis using this more effective way of identifying major food group contributors of energy intake. In addition, we estimate these groups using a large population-based nationwide survey.

\section{Methods}

\section{Sample}

The source of dietary data for the present study was the Brazilian National Dietary Survey, the dietary component of the Household Budget Survey, collected in 2008-9. This is the first and most recent nationwide dietary intake dataset available in Brazil.

The Household Budget Survey was conducted by the Brazilian Office of Geography and Statistics (Instituto Brasileiro de Geografia e Estatistica) and was designed to be representative of all Brazilian households. About 56000 households were selected from a master sample of household surveys. The master sample includes a set of 12800 primary sample units, which were selected by a two-stage sample technique to be used in national household sample surveys. In the first stage, primary sample units were selected according to the number of households, and in the second stage the households were selected by simple random sampling. The primary sample units were stratified according to geographic and economic levels and a random sample of 4696 primary sample units was selected for the Household Budget Survey, allowing assessment of energy intake according to different geographic locations (urban/rural, five Brazilian geographic areas) and economic levels.

The National Dietary Survey was designed to gather information on food consumption in $30 \%$ of the households randomly selected from the 2008-9 Household Budget Survey, with a non-response rate of $19 \%$. This cross-sectional analysis included all respondents over 10 years of age with dietary records in the selected households ( $n$ 34003).

The research protocol of the present study was reviewed and approved by the Ethics Committee of the Institute of Social Medicine at the Rio de Janeiro State University (CAAE 0011.0.259.000-11) in accordance with the Brazilian law no. 5534, which complies with the Helsinki Declaration.

\section{Measurement of dietary intake}

Food records were collected during two non-consecutive days for all individuals aged 10 years and older. The respondents received a booklet with instructions on how to record food intake, which included figures of tableware and other household measures (silverware, plates, glasses, and cups and industrial containers, such as cans and bottles). The records comprised information on foods, culinary preparations and beverages consumed as well as amount, time and place of intake. All records were reviewed by interviewers who probed for commonly forgotten foods, how foods were prepared (e.g. raw, cooked and roasted) and the amount consumed. The interviewers double-checked with the respondents any records with less than five items per $\mathrm{d}$ or periods greater than $3 \mathrm{~h}$ without any intake. Reported food amounts were transformed to grams or millilitres, and energy intake was estimated using a food composition table based on the Brazilian Table of Food Composition and the Nutrient Data System for Research software, version 2008. A total of 1103 respondents provided only $1 \mathrm{~d}$ of food record; therefore, the final analysis of differences between days with and without consumption was conducted among the remaining 32900 participants.

\section{Food grouping}

Dietary intake data collected in the survey were coded into more than 2000 food items. For these analyses, food items representing markers of unhealthy eating based on the Brazilian guidelines ${ }^{(2)}$ : cakes, cookies and desserts; sugarsweetened beverages; soft drinks; processed meats; and savoury snacks were grouped, as well as those considered markers of healthy eating: vegetables, beans, milk and fruit. Meat, white breads and cheese were also grouped. Other food groups, such as whole-wheat bread, brown rice, and nuts, are included in the guidelines, but were not analysed because few people reported them.

\section{Statistical analysis}

Mean energy intake according to the consumption of selected food groups in $1 \mathrm{~d}, 2 \mathrm{~d}$ or none of the days of the two non-consecutive days of food records was calculated to characterise the diet of the study population. The main analysis was performed on the mean energy intake only in individuals who reported consuming the selected food group in one of the $2 \mathrm{~d}$, by comparing the same individual the day with and the day without the specific food intake. This paired analysis accounted for all possible confounding factors, such as age, physical activity, sex and obesity status.

Statistical analysis were conducted using SAS, release 9.1.3 (2003, SAS Institute, Inc.), taking into account the sample design effect. To adjust for differential probabilities of selection and non-response, appropriate weighting factors were applied, allowing inference to the Brazilian population aged 10 years and more. Analysis was preliminarily stratified for sex, but because there were no sex differences, data are shown for the overall population.

\section{Results}

The Brazilian National Dietary Survey was conducted on 34003 respondents aged 10 years or older. In this population, $52 \%$ were women and $79 \%$ were adults ( $\geq 20$ years of age), while adolescents (10-19 years old) represented $21 \%$ of the population. In addition, $49 \%$ of the adults were overweight (BMI $\geq 25 \mathrm{~kg} / \mathrm{m}^{2}$ ), and $20 \%$ of adolescents were classified as 
Table 1. Weighted and age-adjusted mean energy intake (in kJ) according to food group intake reported in $1 \mathrm{~d}, 2 \mathrm{~d}$ or none of the days of the two non-consecutive days of food records (the 2008-9 Brazilian National Dietary Survey)

\begin{tabular}{|c|c|c|c|c|c|c|}
\hline \multirow[b]{2}{*}{ Food groups } & \multicolumn{3}{|c|}{ Men } & \multicolumn{3}{|c|}{ Women } \\
\hline & None & $1 d$ & $2 d$ & None & $1 d$ & $2 d$ \\
\hline Cakes, cookies and desserts & 8054 & 9301 & 10452 & 6381 & 7263 & 8485 \\
\hline Sugar-sweetened beverages & 8109 & 9008 & 9904 & 6573 & 7381 & 8088 \\
\hline Soft drinks & 8368 & 9623 & 10230 & 6849 & 7820 & 8393 \\
\hline Meat & 7318 & 8330 & 9263 & 6309 & 6983 & 7494 \\
\hline Processed meats & 8473 & 9192 & 10406 & 6958 & 7627 & 8364 \\
\hline Vegetables & 8406 & 8987 & 9347 & 6858 & 7305 & 7410 \\
\hline Beans & 8209 & 8598 & 8979 & 6812 & 7096 & 7360 \\
\hline White breads & 8004 & 8786 & 9222 & 6590 & 7117 & 7531 \\
\hline Milk & 8715 & 9167 & 9719 & 7033 & 7607 & 7715 \\
\hline Cheese & 8560 & 9556 & 9862 & 6933 & 7778 & 8109 \\
\hline Fruit & 8293 & 9326 & 9866 & 6766 & 7368 & 7904 \\
\hline Savoury snacks & 8757 & 9979 & 10627 & 7125 & 8226 & 8703 \\
\hline Overall energy intake* & 8812 & & & 7213 & & \\
\hline
\end{tabular}

${ }^{*}$ Average energy intake of the population.

overweight, according to the WHO cut-off for BMI-for-age $(z \text {-scores }>+1 \mathrm{sD})^{(8)}$.

In total, energy and mean energy intakes according to food group intake reported in $1 \mathrm{~d}, 2 \mathrm{~d}$ or none of the days of the two non-consecutive days of food records are shown in Table 1. In all food groups, energy intake increased according to the number of days with consumption of the specific food, with all trends being statistically significant $(P$-values $<0 \cdot 001)$. Men and women reporting $2 \mathrm{~d}$ without intake of meat showed the lowest mean energy intake, whereas those reporting $2 \mathrm{~d}$ with intake of savoury snacks showed the highest energy intake. Men reporting savoury snacks in $2 \mathrm{~d}$ had an energy intake of $10627 \mathrm{~kJ}$ ( $2540 \mathrm{kcal}$ ), which is $20.6 \%$ higher than the mean energy intake for all men. For women, this value was $8702 \mathrm{~kJ}(2080 \mathrm{kcal})$, which also corresponds to $20 \cdot 6 \%$ greater than the mean energy intake for all women.

In an additional analysis, we compared values between individuals reporting intake of a food group in $2 \mathrm{~d}$ (last column in Table 1), considering those individuals as usual consumers of the reported food group.

All comparisons of energy intake according to food groups were age-adjusted; however, other confounders may contribute to these differences in cross-sectional studies. Therefore, we conducted an innovative analysis comparing days with and without the food group intake in each individual, allowing a more direct comparison of the impact of the intake of specific foods on the overall energy intake (Table 2). This comparison more clearly indicates the major contributors to energy intake. Cakes, cookies and other desserts were associated with a difference in energy intake of $992 \mathrm{~kJ}(237 \mathrm{kcal})$, which represents an increase of $12 \%$ in the overall mean energy intake of about $8000 \mathrm{~kJ}$ (approximately $1900 \mathrm{kcal}$ ). Savoury snacks were the second most important contributor with $665 \mathrm{~kJ}(159 \mathrm{kcal})$. The only group for which intake was related to a decrease in energy intake was the vegetable group, which does not include potatoes or other roots (Table 2). A similar analysis stratified by sex showed similar results; most of the difference between days with and without the food group intake showed the same magnitude as contributor to energy intake, with values greater among men. For example, the contribution to energy intake for cakes and sweets was $1129 \mathrm{~kJ}(270 \mathrm{kcal})$ among men and $874 \mathrm{~kJ}$ (209 kcal) among women, with an overall value of $991 \mathrm{~kJ}$ (237 kcal) (data not shown).

\section{Discussion}

Identification of food sources of energy and nutrients in representative samples of the population is a necessary step to define feasible and appropriate dietary recommendations. In addition, the identification of major sources of energy is particularly needed to help with public health efforts to curb the obesity epidemic. Our analysis contributes to this topic, suggesting a new method to define food sources of energy and nutrients.

Table 2. Sample size of participants with and without the intake of food groups, mean difference in total energy intake (in kJ) between day with and without food group consumption and $95 \% \mathrm{Cl}$ of the difference (the 2008-9 Brazilian National Dietary Survey)

(Number of participants, mean difference values and $95 \%$ confidence intervals)

\begin{tabular}{lccc}
\hline Food groups & \multicolumn{3}{c}{$\begin{array}{c}\text { Mean } \\
\text { difference }\end{array}$} \\
\hline Cakes, cookies and desserts & 9934 Cl \\
Sugar-sweetened beverages & 9665 & 992 & 883,1096 \\
Soft drinks & 7062 & 469 & 464,711 \\
Meat & 9993 & 577 & 310,628 \\
Processed meats & 7253 & 343 & 460,699 \\
Vegetables & 8326 & -155 & $-272,481$ \\
Beans & 7651 & 243 & 96,385 \\
White breads & 8991 & 397 & 280,510 \\
Milk & 5593 & 188 & 46,331 \\
Cheese & 4917 & 657 & 494,824 \\
Fruit & 8449 & 180 & 50,264 \\
Savoury snacks & 1559 & 665 & 364,1268 \\
\hline
\end{tabular}


The usual method of identification of food sources of energy intake ${ }^{(6,7,9)}$ calculates the percentage of energy intake from specific food groups, which does not directly translate into dietary recommendations because food choice may be related to sex, obesity status and socioeconomic factors ${ }^{(10-12)}$. We compared this traditional method with an innovative one, which identified the greatest contributors of energy intake according to energy intake as measured by the difference between days with and without the intake of a specific food group. Our novel method of comparing differences in the same person does not require adjustment for other factors associated with food choice. The presented results indicated that, except for savoury snacks, which was the greatest contributor to energy intake using both methods, all other food groups were highly influenced by sex in the traditional method. Our new method requires food records from at least $2 \mathrm{~d}$. This approach has been done in most studies since at least $2 \mathrm{~d}$ is also necessary for estimating usual nutrient and food intake.

The presented results showed that vegetables may play an important role in the public health effort to reduce energy intake, whereas meat and cheese, although important sources of nutrients, are major contributors to energy intake. As expected, SSB, soft drinks, savoury snacks, cakes, cookies and desserts were major contributors of energy intake, supporting their role as markers of unhealthy eating, as shown in the Brazilian guidelines as items to be reduced or avoided ${ }^{(2)}$.

In accordance with our findings, the effect of cheap industrialised items such as cakes, cookies and savoury snacks on energy intake has been discussed by other authors, who have indicated an important role of industrialised items in the obesity epidemic ${ }^{(13,14)}$. Enhancement of flavours associated with low costs promotes over-consumption ${ }^{(13)}$. Moreover, these items are usually consumed between meals as snacks, which has been positively associated with weight gain $^{(15)}$. Not only SSB, but also $100 \%$ fruit juice is associated with weight gain in a pooled analysis of three large cohorts in the United States ${ }^{(16)}$. A school intervention study in Brazil also showed significant addition of sugar in all kinds of beverages ${ }^{(17)}$.

The strengths of the present study include its very large population-based sample of Brazil, covering all regions and different socioeconomic levels of the country. One limitation of the study is that the results are known to under-estimate energy intake in $17 \%$ of participants and that this underestimation is greater among women than among men ${ }^{(18)}$. These findings are consistent with those of other studies using 24-h recall or dietary records in Brazil ${ }^{(19)}$ and elsewhere $^{(20)}$. Under-reporting on specific food groups is possible; however, the impact of this possible bias is unknown in our analysis. Since women tend to under-report more than men ${ }^{(19)}$, our analysis combining men and women may have minimised this possible bias, and the intraindividual comparisons also minimise the role of differential under-reporting.

The advantage of the present analysis is the simplicity of comparing food intake between days with and without certain foods to identify important food markers of inadequate dietary patterns, which could be useful for population monitoring and nutrition education.

\section{Acknowledgements}

The survey was funding by the Ministry of Health of Brazil (agreement no. 4652/2005; grant no. 25000.202044/2005-16). I. N. B., A. d. M. S. and M. C. A. received a fellowship from the Brazilian Federal Agency for the Improvement of Higher Education (CAPES) - process no. 6748-10-4, 454411-0 and 17263/12-3, respectively.

The authors' contributions are as follows: R. S., E. M. Y. and R. A. P. coordinated the research and study design, data management, statistical analysis, interpretation and writing of the manuscript; I. N. B. involved in managing the data, supervising the data collection and defining the portion sizes and in the writing of the manuscript; M. C. A. contributed to data management and definition of nutrient composition database and to the writing of the manuscript; A. d. M. S. contributed to data management, food grouping and manuscript writing. All the authors contributed to the writing of the manuscript and approved the final version of the manuscript.

None of the authors has conflicts of interest.

\section{References}

1. World Health Organization (2011) Global Status Report on Noncommunicable Diseases 2010. Geneva: World Health Organization. http://www.who.int/nmh/publications/ncd_ report2010/en (accessed 5 September 2011).

2. BRASIL, Ministério da Saúde, Secretária de Atenção à Saúde, Coordenação-Geral da Política de Alimentação e Nutrição (2006) Guia alimentar para a população brasileira: promovendo a alimentação saudável (Dietary Guidelines for the Brazilian Population: Promoting Healthy Eating), 210 p. Brasília, DF (Série A. Normas e manuais técnicos). http:// 189.28.128.100/nutricao/docs/geral/guia_alimentar_conteudo. pdf (accessed 20 May 2011)

3. US Department of Agriculture (2010) Report of the Dietary Guidelines Advisory Committee on the Dietary Guidelines for Americans, 2010. Washington, DC: US Department of Agriculture.

4. Health Canada (2007) Eating Well with Canada's Food Guide. Canada: Her Majesty the Queen in Right of Canada, represented by the Minister of Health Canada. http://www.hc-sc.gc.ca/fn-an/food-guide-aliment/index-eng. php (accessed 15 August 2011).

5. Food Standards Agency (FSA) (2006) Nutrient and food based guidelines for UK institutions. http://www.food.gov. uk/multimedia/pdfs/nutguideuk.pdf (accessed 15 August 2011).

6. O'neal CE, Keast DR, Fulgoni VL, et al. (2012) Food sources of energy and nutrients among adults in the US: NHANES 2003-2006. Nutrients 4, 2097-2120.

7. Bezerra IN, Goldman J, Souza AM, et al. (2014) Difference in adult food group intake by sex and age groups comparing Brazil and United States nationwide surveys. Nutr J 13, 74.

8. de Onis M, Onyango AW, Borghi E, et al. (2007) Development of a WHO growth reference for school-aged children and adolescents. Bull World Health Organ 85, 660-667.

9. Sette S, Le Donne C, Piccinelli R, et al. (2013) The third National Food Consumption Survey, INRAN-SCAI 2005-06: 
major dietary sources of nutrients in Italy. Int J Food Sci Nutr 64, 1014-1021.

10. Boek S, Bianco-Simeral S, Chan K, et al. (2012) Gender and race are significant determinants of students' food choices on a college campus. J Nutr Educ Behav 44, 372-378.

11. Breslow RA, Guenther PM, Juan W, et al. (2010) Alcoholic beverage consumption, nutrient intakes, and diet quality in the US adult population, 1999-2006. J Am Diet Assoc 10, $551-562$

12. Araujo MC, Verly Junior E, Junger WL, et al. (2014) Independent associations of income and education with nutrient intakes in Brazilian adults: 2008-2009 National Dietary Survey. Public Health Nutr 17, 2740-2752.

13. Monteiro CA, Levy RB, Claro RM, et al. (2011) Increasing consumption of ultra-processed foods and likely impact on human health: evidence from Brazil. Public Health Nutr 14, 5-13.

14. Moubarac JC, Martins AP, Claro RM, et al. (2013) Increasing consumption of ultra-processed foods and likely impact on human health. Evidence from Canada. Public Health Nutr 16, 2240-2248.

15. Bes-Rastrollo M, Sanchez-Villegas A, Basterra-Gortari FJ, et al (2010) Prospective study of self-reported usual snacking and weight gain in a Mediterranean cohort: the SUN project. Clin Nutr 29, 323-330.

16. Mozaffarian D, Hao T, Rimm EB, et al. (2011) Changes in diet and lifestyle and long-term weight gain in women and men. $N$ Engl J Med 364, 2392-2404

17. Sichieri R, Paula Trotte A, de Souza RA, et al. (2009) School randomized trial on prevention of excessive weight gain by discouraging students from drinking sodas. Public Health Nutr 12, 197-202.

18. Lopes TS, Ferrioli E, Pfrimer K, et al. (2010) Validation of energy intake estimated by the food record applied in a Brazilian national individual dietary survey by the double label water method. Public Health Nutr 13, 326.

19. Scagliusi FB, Ferriolli E, Pfrimer K, et al. (2008) Underreporting of energy intake in Brazilian women varies according to dietary assessment: a cross-sectional study using doubly labeled water. J Am Diet Assoc 108, 2031-2040.

20. Poslusna K, Ruprich J, de Vries JH, et al. (2009) Misreporting of energy and micronutrient intake estimated by food records and 24 hour recalls, control and adjustment methods in practice. Br J Nutr 101, Suppl. 2, S73-S85. 